\title{
The results of anterior transposition of the inferior oblique: anterior fibres sutured to sclera versus bunch-up technique
}

\author{
Abstract \\ Purpose: To evaluate the results of 2 different surgical techniques of anterior transposition \\ of the inferior oblique (IOAT) in patients with dissociated vertical deviation (DVD): \\ anterior fibres sutured to sclera versus bunch-up technique. \\ Methods: 121patients were included: group 1: In 41patients (82eyes) only the anterior \\ fibers of the IO adjacent were placed to the temporal corner of the inferior rectus insertion; \\ group 2: In 80patients (160eyes), the anterior and posterior fibers were bunch-up and \\ sutured near the temporal corner of the inferior rectus insertion. \\ Results: The DVD values were measured and calculated for right eye/left eye (RE/LE) in \\ prism dioptres (PD). Group 1: The values of DVD decreased from pre-operative RE/LE 8, \\ 82/8, 36PD to a post-operative of RE/LE 1, 33/1, 13PD. None of the patient had limitation \\ of elevation. Group 2: The values of DVD decreased from pre-operative values of RE/LE \\ 12, 98/10, 67PD to RE/LE 3, 47/2, 18PD post-operatives. \\ When DVD $\leq 15 \mathrm{PD}$, DVD. \\ Group 1: from pre-operative RE/LE 8, 08/7, 72PD to post-operative RE/LE 1, 44/0, 77 PD. \\ Group 2: from pre-operative RE/LE 10, 90/10, 16 PD to post-operative RE/LE 1,84/1, \\ 41PD. \\ When DVD $>15$ PD \\ Group 1: from pre-operative RE/LE 20/10PD to post-operative RE/LE 10/0 PD. \\ Group 2: from pre-operative RE/LE 20/20PD to post-operative RE/LE 6/6PD. \\ In patients from group 2, limitation of elevation in abduction followed, mild in 34 and \\ moderate in 9 patients, 2 had antielvation syndrome (AHS). \\ Conclusion: IOAT with only anterior fibers of the inferior oblique sutured to sclera is a safe \\ and effective procedure for DVD correction, especially when DVD $\leq 15 \mathrm{PD}$. The bunch-up \\ technique may cause limitation of elevation and AHS.
}

Volume 6 Issue 2 - 2017

Luminita Teodorescu, IA Velcea

Department of Paediatric Ophthalmology, Oftalmix SOP

Ophthalmology Clinic, Romania

Correspondence: Luminita Teodorescu, Oftalmix SOP Ophthalmology Clinic, Bucharest Romania Str Turturelelor nr I I B bl A ap A03 A04 Sector 3 Bucuresti, Romania, Tel 0722 500935, Email luminita.teodorescu@oftalmix.ro

Received: December 12, 2016 | Published: February 8, 2017
Abbreviations: IOAT, anterior transposition of the inferior oblique; DVD, dissociated vertical deviation; PD, prism dioptres; RE, right eye; LE, left eye; AHS, antielvation syndrome; DSC, dissociated strabismus complex; IO, oblique muscle; SR, rectus muscle; IR, inferior rectus; AES, anti-elevation syndrome

\section{Introduction}

Dissociated strabismus complex (DSC) includes dissociated horizontal, vertical, torsional deviation, latent nystagmus and sub-normal binocularity. ${ }^{1}$ It is usually bilateral but asymmetric; may manifest spontaneously or with cover testing. As clinical manifestation, DSC is a comitant drift of both eyes: the fixating eye manifests depression, adduction and intorsion and the non-fixating eye manifests elevation, abduction and extorsion to compensate for the drift of the fixating eye. A reversal of these movements is seen with refixation. ${ }^{2,3}$ The upward vertical version is produced mostly by the inferior oblique muscle (IO) of the fixing eye and the superior rectus muscle (SR) of the non-fixing eye. ${ }^{3}$

The surgical options for DVD correction are:

i. IO anterior transposition (IOAT) in DVD with IOOA (inferior oblique over action) - for treatment of both DVD and IOOA. ii. SR recession in DVD without IOOA: symmetrical, bilateral and large.

iii. Inferior rectus (IR) resection in residual DVD.

iv. In $\mathrm{V}$ pattern with IOOA: anterior and nasal transposition of the inferior oblique (IO).

v. In A pattern with SOOA (superior oblique over action): SR recession and SO posterior tenectomy or 4 oblique muscles weakening procedure.

vi. Horizontal muscle surgery when horizontal deviation or DHD co-exist.

\section{Methods}

The surgical technique of IOAT had changed over time. The reason for using IOAT in DVD is that in up-gaze, contraction of the transposed IO limits elevation and the IO muscle is converted from an elevator into a depressor. ${ }^{4}$ First the "spread out technique" was used; the insertion of the IO was spread out concentric with limbus. This new insertion created a "J deformity", ${ }_{4}$ and anti-elevation syndrome (AES) occurred frequently with extorsion in up-gaze. ${ }^{5}$ Than the "bunch up technique "was used, bunching together the anterior and 
posterior fibers of the IO. This technique was also followed by AES in long term follow-up. In the new technique only the anterior fibers of IO were sutured to the temporal corner of the IR insertion (Figure 1).

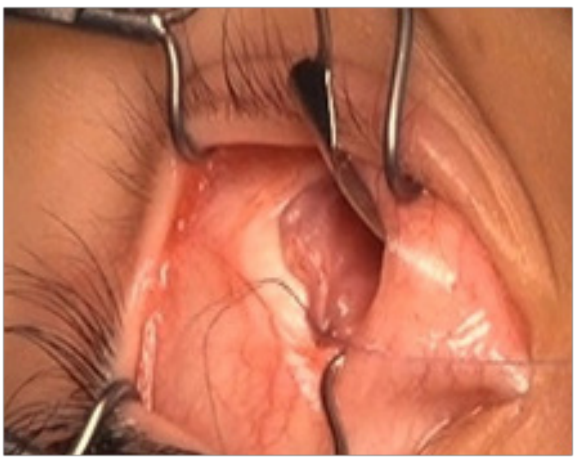

Figure I Anterior fibers of IO sutured near the temporal corner of the IR insertion.

The study included 121patients with DVD operated in our clinic between 2000 and 2013. Group 1 included 41patients (82eyes), mean age 59, 72months (10-178months), follow up 4, 21 (4-10months). Only the anterior fibers of the IO adjacent were placed near the temporal corner of the inferior rectus insertion. Group 2 included 80 patients (160eyes). The anterior and posterior fibers were bunch-up and sutured near the temporal corner of the inferior rectus insertion. The posterior fibers were kept $3 \mathrm{~mm}$ posterior to IR insertion in order to avoid "J" deformity. ${ }^{6}$ In both groups, bilateral symmetric IOAT was done in all cases, irrespective of DVD asymmetry. Horizontal muscle surgery was added when necessary: in 103patients for esotropia, 8patients for exotropia, 10patients had no horizontal strabismus and only IOAT was done.

\section{Results}

The DVD values were measured and calculated for right eye/ left eye $(\mathrm{RE} / \mathrm{LE})$ in prism dioptres $(\mathrm{PD})$. Group 1: The values of DVD decreased from pre-operative RE/LE 8, 82/8, 36PD to a postoperative of RE/LE 1, 33/1, 13PD. None of the patient had limitation of elevation.

Group 2: The values of DVD decreased from pre-operative values of RE/LE 12, 98/10, 67 PD to RE/LE 3, 47/2, 18 PD post-operatives.

a. When DVD $\leq 15 P D$, DVD.

b. Group1: from pre-operative RE/LE $8,08 / 7,72 \mathrm{PD}$ to postoperative RE/LE 1, 44/0, 77PD.

c. Group 2: from pre-operative RE/LE 10, 90/10, 16 PD to postoperative RE/LE 1,84/1, 41 PD.

d. When DVD $>15 P D$

e. Group1: from pre-operative RE/LE 20/10PD to post-operative RE/LE 10/0PD.

f. Group 2: from pre-operative RE/LE 20/20 PD to post-operative RE/LE 6/6 PD.

In patients from group 2, limitation of elevation in abduction followed, mild in 34 and moderate in 9patients, 2 had antielvation syndrome (AHS). Residual DVD may result after IOAT using either of these 2techniques. 10 from 80patients from group $2(12,1 \%)$ required re-operations for residual DVD. Similar results were obtained by other authors, ${ }^{7,8}$ (Table 1).

Table I Results of surgery in DVD using IOAT-AF in group I and IOAT-bunch technique in group 2

\begin{tabular}{|c|c|c|}
\hline & Group I & Group 2 \\
\hline Number of pts & 4I (82eyes) & 80 (160eyes) \\
\hline Age (in months) & $\begin{array}{l}10-178 \\
\text { mean age } 59,72\end{array}$ & $\begin{array}{l}\text { I7-228 } \\
\text { Mean age } 64,60\end{array}$ \\
\hline Follow-up (in months) & $\begin{array}{l}4-10 \text { months } \\
\text { mean } 4,21\end{array}$ & $\begin{array}{l}4-156 \\
\text { Mean } 31,25\end{array}$ \\
\hline Surgical technique & IOAT- AF & IOAT-bunch \\
\hline $\begin{array}{l}\text { DVD } \\
\text { Preoperative OD/OS/Asymmetry } \\
\text { (Minimum, maximum) }\end{array}$ & $\begin{array}{l}8,82 / 8,36 / 0,46 \\
(\min 0, \max 20)\end{array}$ & $\begin{array}{l}|2,98 /| 0,67 / 2,3 \mid \\
(\min 0-\max 25)\end{array}$ \\
\hline $\begin{array}{l}\text { Postoperative OD/OS/Asymmetry } \\
\text { (Minimum, maximum) }\end{array}$ & $\begin{array}{l}1,33 / 1,13 / 0,29 \\
(\min 0, \max 18)\end{array}$ & $\begin{array}{l}3,47 / 2,18 / 1,29 \\
(\min 0, \max 18)\end{array}$ \\
\hline \multicolumn{3}{|l|}{$D V D \leq 15$} \\
\hline Preoperative OD/OS/Asymmetry & $8,08 / 7,72 / 0,36$ & $10,90 / 10,16 / 0,74$ \\
\hline Postoperative OD/OS/Asymmetry & $\mathrm{I}, 44 / 0,77 / 0,67$ & $\mathrm{I}, 84 / \mathrm{I}, 4 \mathrm{I} / 0,43$ \\
\hline $\begin{array}{l}\text { DVD>15 PD } \\
\text { Preoperative OD/OS/Asymmetry }\end{array}$ & $20 / 10 / 10$ & $20 / 20 / 0$ \\
\hline Postoperative OD/OS/Asymmetry & $10 / 0 / 10$ & $6 / 6 / 0$ \\
\hline Limitation of elevation in abduction & 0 & $\begin{array}{l}\text { Mild in } 34 \text { pts, } \\
\text { Moderate in } 9\end{array}$ \\
\hline Limitation of elevation in straight up-gaze & 0 & 8 \\
\hline AES & 0 & 2 \\
\hline
\end{tabular}

Pts, patients; DVD, dissociated vertical deviation; PD, prism dioptres; IOAT- AF, only the anterior fibers of the $\mathrm{IO}$ adjacent were placed near the temporal corner of the inferior rectus insertion; IOAT-bunch, the anterior and posterior fibers were bunch-up and sutured near the temporal corner of the inferior rectus insertion with the posterior fibers was kept $3 \mathrm{~mm}$ posterior to IR insertion; $\mathrm{AES}$, antielevation syndrome

\section{Discussion}

The risk of AHS increases after lateral placement of the posterior fibers. ${ }^{9}$ Placing the posterior fibers further temporal to the $\mathrm{Y}$ axis may cause substantial extorsion with $\mathrm{Y}$ or $\mathrm{T}$ pattern. ${ }^{10}$ Anti-elevation in abduction following IOAT can be caused by extorsion. ${ }^{11}$ The risk of AHS increases also after IOAT with IO resection. ${ }^{12}$ In order to avoid AHS, in group1, the posterior fibers were freely left hanged back. In all our patients surgery was bilateral and symmetrical and IO was placed at the IR insertion. Few of the reasons were that although DVD and IOOA may be observed unilaterally, but after unilateral surgery DVD or IOOA may become prominent in the other eye. Also, unilateral IOAT can result in lower lid asymmetry.

\section{Conclusion}

Our results suggested that IOAT with only the anterior fibers of the IO sutured to sclera is a safe and effective procedure for DVD 
correction, with no postoperative hypotropia or elevation deficit. We prefer to use this technique when $\mathrm{DVD} \leq 15 \mathrm{PD}$ because is effective, without having the risk of AES. When pre-operative DVD $>15 P D$ we use the IOAT "bunch-up" technique only in very asymmetrical DVD cases, IOAT "bunch-up" technique in the eye with larger DVD and anterior fibers IOAT in the other eye. We use to perform moderate bilateral SR recession $6-7 \mathrm{~mm}$ as a second procedure for residual DVD, We are aware about the limitations of this study: group 1 is much smaller than group 2, in group 1 the follow-up is shorter (4-10versus 4-156months); there are only 2patients from group 1 with pre-operative DVD $>15 \mathrm{PD}$.

\section{Acknowledgments}

None.

\section{Conflicts of interest}

The authors declare that there is no conflict of interest.

\section{Funding}

None.

\section{References}

1. Wilson ME, Saunders RP. Dissociated Deviations, Pediatric Ophthalmology. Current thoughts and a practical guide, SpringerVerlag Berlin Heidelberg, USA. 2009;153-161.

2. Brodsky MC. DVD remains a moving target!. JAAPOS. 1999;3(6):325-327.
3. Guyton DL. Dissociated vertical deviation: etiology, mechanism and associated phenomena. Costenbader lectures. JAAPOS. 2000;4(3):131-144.

4. Stager DR, Weakley DR, Stager D. Anterior transposition of the inferior oblique. Anatomic assessment of the neurovascular bundle. Arch Ophthlmol. 1992;110(3):360-362.

5. Santiago AP, Rosenbaum AL. Dissociated vertical deviation. In: Rosenbaum AL, Santiago AP, Editors. Clinical Strabismus Management. 1st edn, WB Saunders Company, Philadelphia, USA. $1999 ; 237-247$.

6. Guemes A, Wright KW. Effect of graded anterior transposition of the inferior oblique muscle on versions and vertical deviation in primary position. JAAPOS. 1998;2(4):201-206.

7. Balci YG, Ozkan S. Transaction of the $31^{\text {st }}$ ESA Meeting. 2007.

8. Gamio S. Second surgery in DVD. JAAPOS. 2011;15(1):18-19.

9. Mims JL, Wood RC. Antielevation syndrome after bilateral anterior transposition of the inferior oblique muscles: Incidence and prevention. JAAPOS. 1999;3(6):333-336.

10. Kushner BJ. Torsion as a contributing cause of the anti-elevation syndrom. JAAPOS. 2001;5(3):172-177.

11. Ellis FJ, Guyton DL. Mechanism of action of the inferior oblique following anterior transposition. Ophthalmology. 1998;105:544-551.

12. Quinn AG, Kraft SP, Day C, et al. A prospective evaluation of anterior transposition of the inferior oblique muscle, with and without Resection, in the treatment of dissociated vertical deviation. JAAPOS. 2000;4(6):348-353. 